\title{
Stem cell therapy for muscular dystrophies
}

\author{
Stefano Biressi, ${ }^{1,2}$ Antonio Filareto, ${ }^{3}$ and Thomas A. Rando $0^{4,5,6}$ \\ 'Department of Cellular, Computational and Integrative Biology (CIBIO) and ²Dulbecco Telethon Institute, University of Trento, Povo, Italy. ${ }^{3}$ Department of Research Beyond Borders, Regenerative Medicine, \\ Boehringer Ingelheim Pharmaceuticals Inc., Ridgefield, Conneticut, USA. ${ }^{4}$ Department of Neurology and Neurological Sciences and ${ }^{5}$ Paul F. Glenn Center for the Biology of Aging, Stanford University School \\ of Medicine, Stanford, California, USA. ${ }^{6}$ Center for Tissue Regeneration, Repair and Restoration, Veterans Affairs Palo Alto Health Care System, Palo Alto, California, USA.
}

\begin{abstract}
Muscular dystrophies are a heterogeneous group of genetic diseases, characterized by progressive degeneration of skeletal and cardiac muscle. Despite the intense investigation of different therapeutic options, a definitive treatment has not been developed for this debilitating class of pathologies. Cell-based therapies in muscular dystrophies have been pursued experimentally for the last three decades. Several cell types with different characteristics and tissues of origin, including myogenic stem and progenitor cells, stromal cells, and pluripotent stem cells, have been investigated over the years and have recently entered in the clinical arena with mixed results. In this Review, we do a roundup of the past attempts and describe the updated status of cell-based therapies aimed at counteracting the skeletal and cardiac myopathy present in dystrophic patients. We present current challenges, summarize recent progress, and make recommendations for future research and clinical trials.
\end{abstract}

\section{Introduction}

Muscular dystrophies comprise a heterogeneous group of genetic disorders characterized by progressive muscle wasting and weakness $(1,2)$. In muscular dystrophies, muscle dysfunction arises from the mutations of genes encoding different cellular components, including proteins associated with the sarcolemma, extracellular matrix, nuclear membrane, and sarcomeric apparatus (3, 4). Different forms of dystrophy differ in terms of age of onset, severity of symptomatic progression, and distribution of affected muscles $(1,3)$. Depending on the molecular etiology, muscular dystrophies can present clinically relevant defects beyond the skeletal muscle compartment (3). In particular, cardiac involvement is present in several forms of dystrophy $(3,5)$.

With an incidence of approximately 1 in 5000 male newborns, Duchenne muscular dystrophy (DMD; OMIM 310200) is the most frequent and one of the most severe forms of muscular dystrophy $(1,3)$. DMD patients typically present with progressive weakness of limb muscles, trunk muscles, and the diaphragm, leading to wasting, kyphoscoliosis, and severe respiratory problems $(1,2)$. Most patients die in their third decade of life due to respiratory complications $(1,2)$. Almost all DMD patients have cardiac involvement, and heart failure is the second leading cause of death (5). Cardiac abnormalities, such as dilated and hypertrophic cardiomyopathy, increase with age (6). A rarer ( 1 in 20,000 male births) and clinically milder form of dystrophy, Becker muscular dystrophy (BMD; OMIM 300376) has the same causative allele as DMD (1, 3). Onset of BMD symptoms occurs later than in $\mathrm{DMD}$, and the average age of death is in the fifth decade of life (1). Almost $50 \%$ of BMD deaths occur due to congestive heart failure and arrhythmias (7).

Conflict of interest: AF is currently an employee of Boehringer Ingelheim Pharmaceuticals.

Copyright: (5) 2020, American Society for Clinical Investigation.

Reference information: J Clin Invest. 2020;130(11):5652-5664.

https://doi.org/10.1172/JCl142031.
DMD and BMD are caused by mutations in the DMD gene, encoding dystrophin (8). Different types of mutations in the DMD gene, which is located on the $\mathrm{X}$ chromosome and is the largest known gene of the human genome, cause DMD (8). Whereas DMD patients lack the dystrophin protein because of frameshift mutations, BMD is generally caused by mutations that do not disrupt the translational reading frame (9). A partially functional dystrophin is typically expressed in BMD patients (9).

Dystrophin is a component of a plasma membrane-associated complex called the dystrophin glycoprotein complex (DGC), which acts as a framework to connect the intracellular cytoskeleton to the surrounding extracellular matrix (10). The DGC's crucial role for proper muscle functionality and integrity is demonstrated by the overlap in pathological features between DMD and a number of dystrophies caused by mutations in genes encoding other components of the DGC (4). The most well-studied mechanism that has been proposed to explain the etiology of DGC-related muscular dystrophies is a loss of membrane integrity as a result of disruption of structural proteins $(11,12)$, but disruption of membrane-associated signaling pathways has also been implicated in pathogenetic processes $(13,14)$. Whatever the pathophysiological processes, dystrophic muscle exhibits cycles of degeneration and regeneration, accompanied by infiltration of inflammatory cells and progressive accumulation of fibrotic and adipose tissues (15).

Although glucocorticoid treatment is associated with reduced disease progression and multidisciplinary care may further improve patient survival, there is currently no definitive cure for DMD and BMD $(16,17)$. However, many promising therapeutic strategies are now under active investigation. Among the most well-studied approaches is gene delivery using viral or nonviral vectors, a strategy that seeks to deliver a functional, even if truncated, version of dystrophin to myofibers (18). As an alternative, interventions that alter mRNA splicing (e.g., exon skipping) or translation (e.g., stop codon suppression) have been studied as ways to generate functional dystrophin proteins even in the face of pathological 


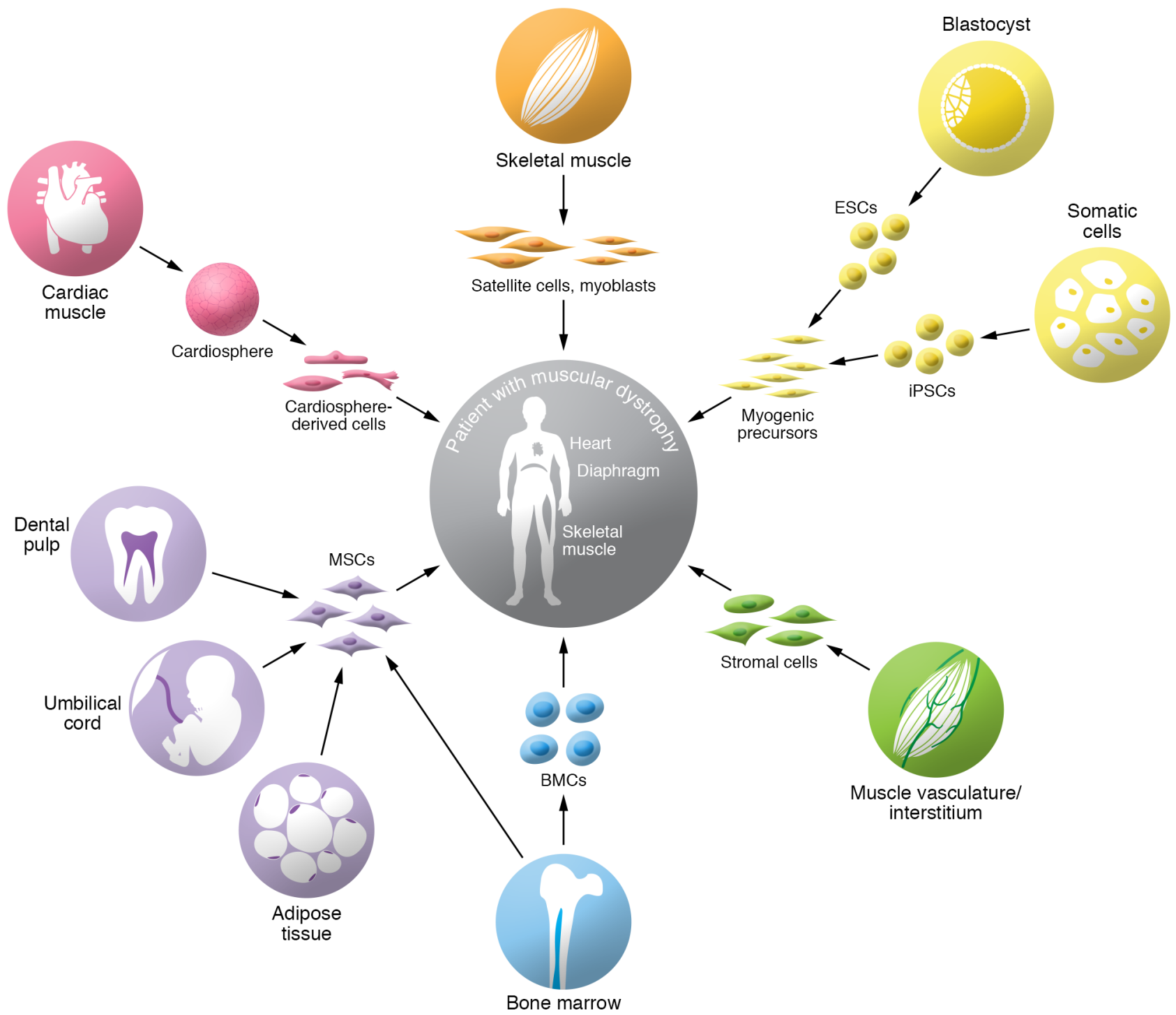

Figure 1. Overview of candidate cell types for cell therapy in muscular dystrophies. Different types of progenitor cells derived from skeletal muscle or from nonmuscle tissues have been tested preclinically or clinically for therapeutic cell transplantation in muscular dystrophies. The identity of the progenitor cells and their tissue of origin are indicated. MSCs, mesenchymal stem cells; iPSCs, induced pluripotent stem cells; ESCs, embryonic stem cells; BMCs, bone marrow-derived cells.

gene mutation (19). More recently, with the advent of gene editing strategies such as transcription activator-like effector nucleases (TALENs), zinc finger nucleases, and CRISPR/Cas9, investigators have sought to directly correct endogenous mutations in $D M D$ and restore its normal reading frame (20). Several pharmacological and genetic approaches striving to reconstruct the DGC complex through overexpression of DGC components, such as utrophin, are also under investigation $(21,22)$. Focusing more on downstream pathogenic mechanisms, pharmacological interventions have targeted pathological consequences of dystrophin mutations including myofiber necrosis, inflammation, fibrosis, ischemia, mitochondrial dysfunction, and aberrant histone deacetylation (22).

This Review focuses on a therapeutic approach that has been envisioned and tested for decades, namely cell-based therapy (Figure 1). The promises of cell therapy are multiple. On one hand, using genetically normal or genetically corrected cells, cell therapy is a gene delivery approach to introduce normal copies of the $D M D$ gene (or other therapeutic genes in nonDMD patients) into myofibers by cell fusion. As a consequence, development of gene correction/complementation strategies is crucial for the successful application of cell therapy, particularly when autologous cells are used as vehicles. In addition, delivery of muscle stem or progenitor cells holds promise to sustain or enhance muscle repair, and possibly populate the muscle stem cell niche for future regenerative demands. Finally, as with many cell-based therapies, cellular vehicles often deliver trophic or even immunomodulatory factors to a tissue that produce a therapeutic benefit. In fact, a growing body of evidence indicates that some progenitors evaluated in cell therapy approaches exert at least part of their regeneration-promoting role through paracrine signals (23). Here, we provide an overview of past attempts and current strategies to use cell-based therapies aimed at ameliorat- 
ing both the skeletal and the cardiac defects in patients affected by muscular dystrophies.

\section{Cell therapy in dystrophic skeletal muscle}

\section{Myogenic stem and progenitor cells from skeletal muscle}

Satellite cells. Skeletal muscle tissue possesses a tremendous capacity for effective self-repair of acute damage (24). Muscle stem cells (MuSCs), also known as satellite cells, are responsible for the muscle regenerative process (25). MuSCs are marked by expression of the transcription factor PAX7 and are required for productive muscle repair (26-28). MuSCs are actively maintained in a quiescent state in adult muscle (29), but can quickly divide following muscle injury, enter the cell cycle, and give rise to proliferating myoblasts that ultimately differentiate and fuse in the process of tissue repair. Activated MuSCs also undergo self-renewal to maintain the population of adult MuSCs (30).

Many studies have demonstrated that transplantation of both mouse and human MuSCs not only promotes regeneration, but transplanted MuSCs also maintain the ability to repopulate the stem cell compartment (31-35). However, several obstacles, such as loss of potency with ex vivo expansion and limited in vivo migration after transplantation, currently hinder the use of these cells for clinical application. As discussed below, strategies aimed at improving these aspects of MuSC transplantation are under active investigation in the preclinical setting (Figure 2).

Myoblasts. Initial studies in dystrophic $m d x$ and $d y / d y$ mutant mice, modeling DMD and merosin-deficient congenital muscular dystrophy, respectively, demonstrated that normal myoblasts, obtained through in vitro expansion of MuSCs, can locally remediate the genetic defect after intramuscular injection $(36,37)$. Substantial effort was therefore invested to enhance the efficacy of myoblast transplantation. The survival and mobility of precursor cells, the extent of distribution of proteins produced by transplanted myoblasts, and the influence of the host environment, including the host immune response elicited by grafted cells, were investigated in different animal models (38). Furthermore, it was shown that some transplanted myoblasts could also survive as muscle precursor cells (39).

Initial observations in mice were rapidly followed by a series of clinical trials in which allogenic myoblasts were expanded in culture and transplanted in the muscles of DMD patients (40). These early studies reported variable expression of donor cell-derived dystrophin and myofiber chimerism, but were inconclusive in terms of functional improvement (41-43). Although discouraging in terms of efficacy, these early studies demonstrated the overall safety of the procedure and revealed the requirement of appropriate immunosuppression (44).

In subsequent years, a series of studies using both murine and human myoblasts, and mainly the $m d x$ model, disclosed several determinants of myoblast engraftment efficacy (45). Myoblast transplants were also performed in large-animal models to more accurately model human physiology $(46,47)$. These studies led to an optimization of transplantation protocols and to further clinical trials in dystrophic patients (Table 1). Major improvements consisted of use of tacrolimus for immunosuppression and increased density of myoblast injection sites $(48,49)$. Indeed, delivery of small volumes of cell suspension through closely spaced (1-2 mm) injections resulted in robust levels of dystrophin expression (48, 49). Data from one patient undergoing myoblast transplantation in a portion of the gastrocnemius muscle showed that donorderived dystrophin was induced in over $30 \%$ of the myofibers at the injection site (49). More recently, a series of studies in nonhuman primates have revealed additional determinants, such as the needle size, cell number, and injection volume (50). These have led to an ongoing phase I/II clinical trial evaluating the effectiveness of high-density delivery of myoblasts in preserving muscle strength in DMD patients (ClinicalTrials.gov NCT02196467) (Table 1).

Notably, a clinical trial reported positive results of myoblast transplantation in patients affected by oculopharyngeal muscular dystrophy (OPMD; OMIM 164300), a form of dystrophy characterized by the selective involvement of the pharyngeal and eyelid muscles. In this study (51), autologous myoblasts obtained from unaffected muscle groups were transplanted into the constrictor muscles of the pharynx of OPMD patients. Most of the patients exhibited stabilization of symptoms up to 2 years after transplantation, and a cell-dose-dependent effect on swallowing was apparent (51).

It is worth noting that the relatively limited amount of muscle tissue affected in OPMD patients allows for focal cell delivery. By contrast, in other types of dystrophies, such as dystrophinopathies, a vastly greater muscle mass is affected, requiring different strategies for cell delivery $(1,2)$. Unfortunately, intra-arterial delivery of myoblasts has proven to be ineffective (52).

Mesoangioblasts. An additional cell type, named mesoangioblasts (MABs) for their ability to differentiate into different mesodermal lineages (including skeletal muscle) and their association with blood vessels, became highly attractive for cell therapy in DMD owing to their ability to efficiently egress a blood vessel wall from the circulation into interstitial muscle tissue, making them a candidate for systemic delivery $(53,54)$. Originally identified in the wall of embryonic dorsal aortae in mice, MABs were also isolated and characterized as a pericyte-derived population of cells from skeletal muscle of adult mice, dogs, and humans $(55,56)$.

Several studies indicated that MABs represent a promising approach to cell therapy in murine models of different muscular dystrophies $(54,55,57-59)$. Furthermore, genetically corrected MABs delivered intra-arterially into dogs with golden retriever muscular dystrophy (GRMD) restored dystrophin expression in $5 \%-50 \%$ of skeletal myofibers in select hind-limb muscles and improved muscle morphology and function (56). In addition to their direct involvement in skeletal muscle regeneration, MABs also have paracrine effects and can modulate immune cell function (60). Transplanted MABs also contribute to the MuSC pool $(54,59,61)$.

These studies led to a phase I/IIa trial (EudraCT 2011-00017633) in five DMD patients (62). The clinical trial involved four intra-arterial infusions of HLA-matched MABs at doses consistent with those administered to dystrophic dogs in preclinical tests (56). Two months after the final infusion, muscle biopsies were collected and analyzed, revealing minimal donor cell engraftment and very modest increase of dystrophin levels (62). Disease progression in one patient was stabilized for more than 2 years, but 
A

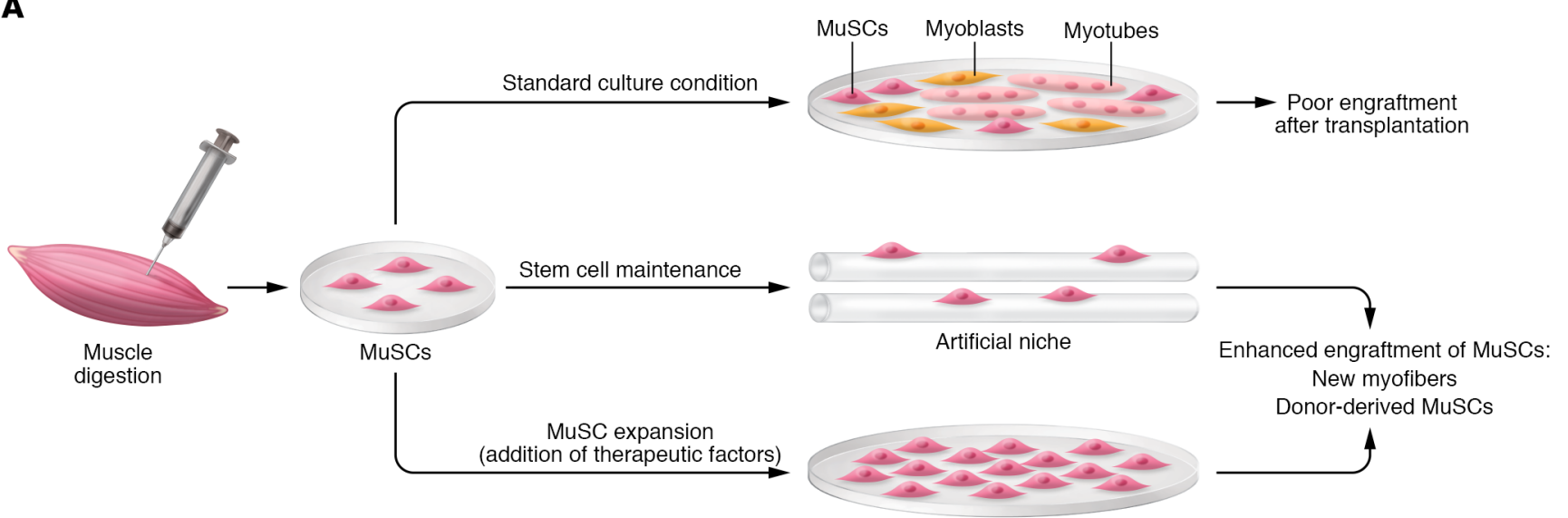

B

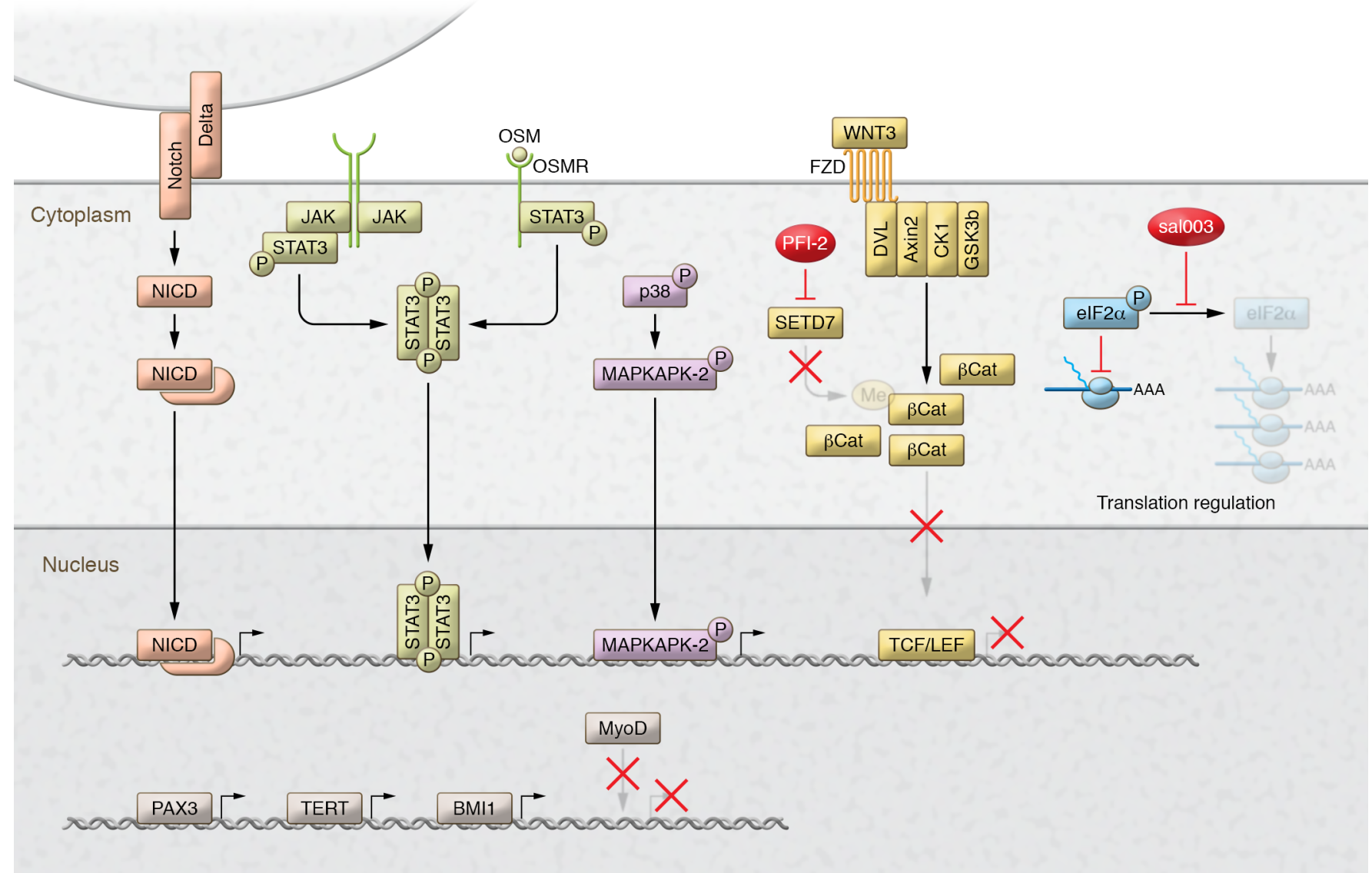

Figure 2. Preservation of potency during in vitro culturing of myogenic cells for cell therapy applications. (A) Expansion of MuSCs isolated from enzymatically digested skeletal muscles under standard culturing conditions on plastic dishes (upper path) selects for myoblasts with poor regenerative and engraftment capability. Two main strategies have been proposed to preserve the in vivo regenerative potential of MuSCs during in vitro culturing and resulted in productive engraftment in preclinical studies. One strategy (middle path) consists of the manipulation of artificial culturing substrates with bioengineering techniques to mimic the niche in which MuSCs reside and stimulate quiescence. The second strategy (lower path) consists of the adoption of culturing conditions favoring the expansion of myogenic progenitors with preserved regenerative potential. (B) Expansion of myogenic progenitors with preserved regenerative potential can be achieved through the addition to the culture medium of factors able to modulate the activity of fundamental signaling pathways, such as the Notch, JAK/STAT, oncostatin M (Osm), and p38 MAPK signaling pathways (34, 138-140, 142); Setd7-dependent epigenetic modifications (143); elF2 $\alpha$-dependent translational control (141); or the genetic alteration of regulators of myogenic lineage progression and proliferation.

no clear correlation with dystrophin expression was apparent. One patient developed atrial fibrillation and a thalamic stroke detected by MRI, highlighting the need for stringent cardiovascular monitoring when intra-arterial delivery of cells is used. Although this clinical trial failed to demonstrate clear efficacy, it provided information essential for future cell therapy trials (Table 2).

Other cell populations with myogenic potential from muscle interstitium. The search for myogenic cells suitable for cell therapy applica- 


\section{Table 1. Selected clinical trials for muscular dystrophies employing myoblasts}

\begin{tabular}{|c|c|c|c|c|c|c|c|}
\hline & & & & & & & \\
\hline & Cell the & apy approach & Dx / no. of & Time point & Outcome & & Reference \\
\hline Donor & Route & Immun. sup. & patients & (mo) & Efficacy & Side effects & or trial ID \\
\hline Parents & i.m. & $\begin{array}{l}\text { Tacrolimus } \\
\text { ( } \pm \text { steroids) }\end{array}$ & $\begin{array}{c}\text { DMD } \\
9\end{array}$ & 1 & $\begin{array}{l}\text { - \% total DYS+ fibers at injection site: } \\
\text { 3.5\%-21.2\% (8/9); } 1 \text { fiber/muscle section } \\
\text { (1/9); noninjected site: } 0-4.6 \%(9 / 9) ; \\
\text { - \% donor-derived DYS+ fibers at injection site: } \\
6.8 \%-13.5 \%(5 / 6) ; 1 \text { fiber/muscle section } \\
\text { (1/6); noninjected site: <0.1\% (6/6); } \\
\text { - presence of donor-derived nuclei }(2 / 2) ; \\
\text { - increased DYS in semiquantitative RT-PCR } \\
\text { (9/9) and qPCR }(3 / 3) ; \\
\text { - } \alpha \text {-sarcoglycan reassembly }(3 / 3)\end{array}$ & $\begin{array}{l}\text { Weight increase }(1 / 3) \text {; diarrhea } \\
(3 / 9) \text {; local immune cell } \\
\text { infiltration }(8 / 9)\end{array}$ & 48 \\
\hline Father & i.m. & Tacrolimus & $\begin{array}{c}\text { DMD } \\
1\end{array}$ & 1 & $\begin{array}{l}\text { - \% donor-derived DYS }{ }^{+} \text {fibers at injection site: } \\
\text { 27.5\%; noninjected site: 0\%; } \\
\text { - increased DYS in RT-PCR } \\
\text { - } 70 \% \text { increase in metacarpal flexion strength } \\
\text { - increased DYS in immunofluorescence; } \\
\text { - } 70 \%-100 \% \text { increase in metacarpal flexion } \\
\text { strength }\end{array}$ & Thumb paresthesia & 49 \\
\hline Allogeneic & & Tacrolimus & $\begin{array}{l}\text { DMD } \\
10\end{array}$ & $2-18$ & Recruiting & & $\begin{array}{c}\text { NCT } \\
02196467\end{array}$ \\
\hline $\begin{array}{l}\text { Autologous } \\
\text { (unaffected muscle) }\end{array}$ & i.m. & & $\begin{array}{l}\text { OPMD } \\
12\end{array}$ & 24 & $\begin{array}{l}\text { - stabilization of pharyngeal propulsion; } \\
\text { - improved upper esophageal sphincter function } \\
\text { (6/12); } \\
\text { - dose-dependent improvement in drinking test }\end{array}$ & & 51 \\
\hline $\begin{array}{l}\text { Autologous } \\
\text { (unaffected muscle) }\end{array}$ & i.m. & & $\begin{array}{l}\text { OPMD } \\
10\end{array}$ & & Ongoing & & $\begin{array}{c}\text { NCT } \\
02878694\end{array}$ \\
\hline
\end{tabular}

The number of patients with a specific parameter is indicated as a fraction of total patients considered. DYS, dystrophin; Immun. sup., immune suppression; qPCR, quantitative PCR; RT-PCR, reverse transcription PCR.

tions in muscle diseases resulted in the identification of several candidates, mainly consisting of stromal cells that can be isolated from skeletal muscles (63). Muscle side population (SP) cells are a population of myogenic progenitors that can be isolated from murine and human muscle based on their ability to extrude Hoechst dye (64). Muscle SP cells, similarly to bone marrow-derived SP cells (65), can home to the skeletal muscles of dystrophic mice after systemic delivery, fusing with limited percentages of host myofibers (66). Moreover, muscle SP cells can give rise to MuSCs upon transplantation (67). Although SP cell engraftment appears to be insufficient to be therapeutically relevant in terms of dystrophin complementation, evidence suggests that SP cells may influence the myogenic program through paracrine mechanisms (68).

A population of cells endowed with myogenic potential was identified in the interstitium of murine skeletal muscle through expression of the stem cell marker PW1 and absence of PAX7 and was therefore named $\mathrm{PW}^{+}{ }^{+} \mathrm{PAX} 7^{-}$interstitial cells (PICs) (69). PICs do not derive from MuSCs, are myogenic in vitro, and contribute to muscle regeneration, as well as generating MuSCs, following transplantation (69). Notably, a subpopulation of interstitial cells that express PW1 and myogenic factor 5 (MYF5), but

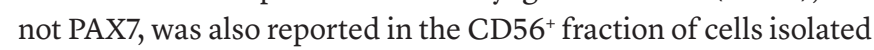
from human muscles (70).

Beyond these, other populations of cells with myogenic potential have been identified based on molecular markers, adhesion properties, or other functional characteristics. These have been studied primarily by single laboratories and include muscle- derived stem cells (MDSCs), MuStem cells, SMALD ${ }^{+}$cells, and smooth muscle-mesenchymal cells (71-74). All have been shown to contribute to new muscle formation upon transplantation (7274). Further molecular characterization is necessary for each of these, as well as identification of the nature and localization of the cells of origin in vivo.

\section{Cells from non-skeletal muscle tissues}

Mesenchymal stem cells. Over the last two decades, different stromal cell types known to exhibit peculiar paracrine/secretory functions have been tested as potential treatments for muscular dystrophies. These mesenchymal stromal cells, often referred to as "mesenchymal stem cells" (MSCs), are under evaluation as potential cellular therapies for different pathological conditions. However, uncertainties remain because of the extreme heterogeneity of such cells obtained from different tissues and based on different criteria (75). Furthermore, it is unclear how paracrine effects are likely to be effective, long-term treatments of chronic, degenerative diseases like muscular dystrophies. Nevertheless, studies using both intramuscular and systemic delivery in different dystrophic mouse models have examined the potential therapeutic efficacy of MSCs of different tissue origin (76-81). Although many studies demonstrate the ability of MSCs to engraft in skeletal muscle, their ability to enhance muscle contractile force is unclear (82). Studies have also suggested the potential of transplanted MSCs to give rise to MuSCs $(76,79)$. Notably, in some of these studies, MSCs derived from nonmurine tissues were suc- 
Table 2. Selected cell therapy clinical trials for DMD involving nonmyoblast cell types

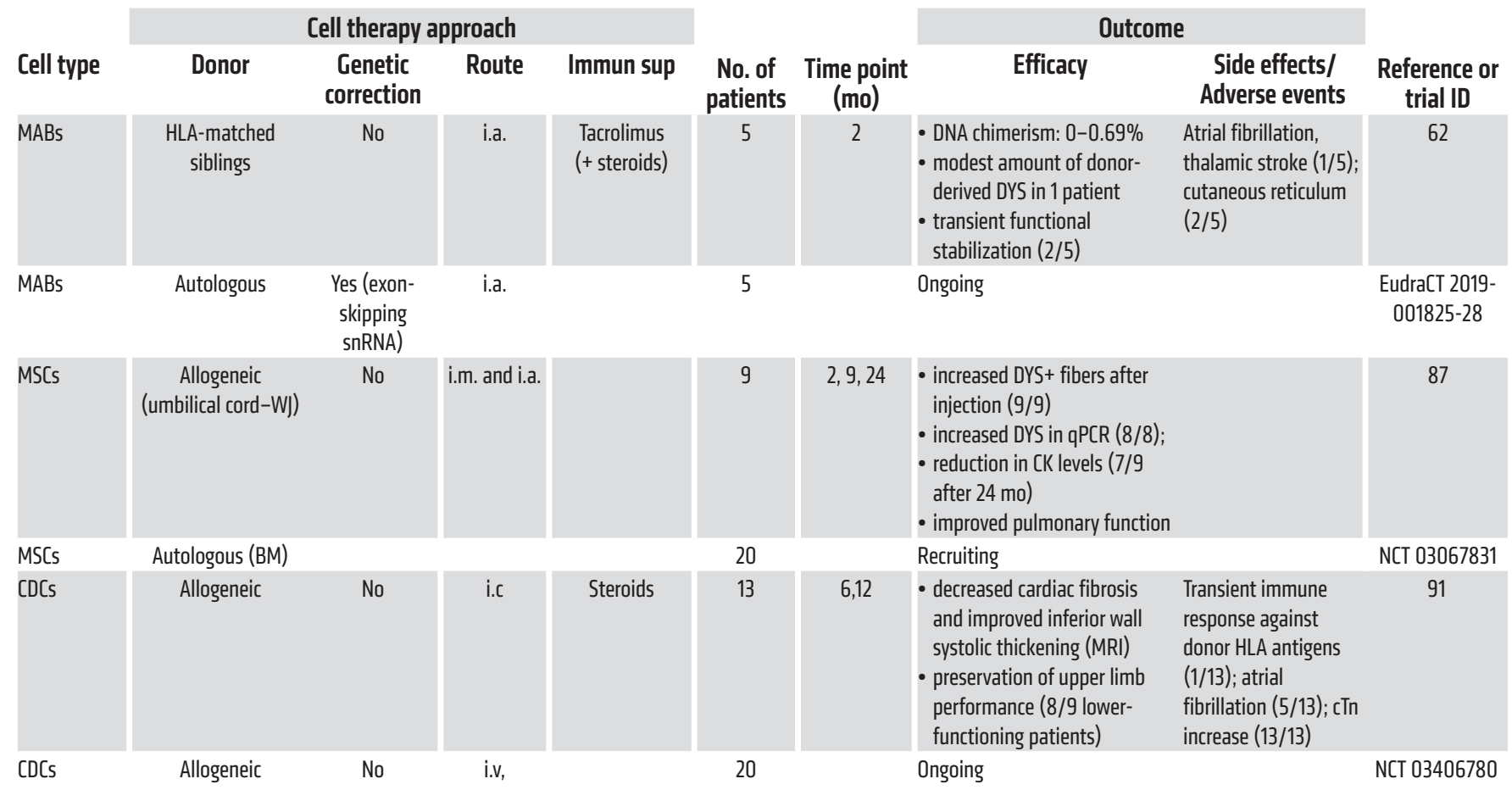

The number of patients with a specific parameter is indicated as a fraction of total patients considered. BM, bone marrow; CK, creatine kinase; $c T n$, cardiac troponin; DYS, dystrophin; i.a., intra-arterial; i.c., intracoronary; Immun. sup., immune suppression; qPCR, quantitative PCR; snRNA, small nuclear RNA; WJ, Wharton jelly.

cessfully transplanted into immune-competent mice, supporting the idea that MSCs have immune-evasive properties (83).

Local and intravenous injections of human adipose-derived stromal cells were able to engraft in muscles of GRMD dogs and express human dystrophin (84). Stromal cells obtained from human dental pulp were administered to GRMD dogs, resulting in significant engraftment in muscles but only modest human dystrophin expression after systemic multiple deliveries (85). These findings support the idea that MSCs may exert antiinflammatory or paracrine effects (23).

The effects of intravenous administration of human umbilical cord-derived MSCs (UC-MSCs) were studied in one pediatric and two adult BMD patients (86). Although histology of muscle biopsies did not reveal any improvement, the clinical examination reported gait improvement in the pediatric patient (86). In a subsequent study, nine DMD patients received a combination of intramuscular and systemic administration of allogeneic UC-MSCs (NCT02484560) (Table 2). Pulmonary function, a readout of diaphragmatic activity, was improved in all patients (87). Variable induction of dystrophin expression was reported in all patients, and although limb muscle strength was not significantly different between pre- and post-treatment, the majority of the treated patients exhibited a reduction in creatine kinase levels (87).

Cardiosphere-derived cells. Recent evidence suggests a promising role of a cardiac population of stromal cells, referred to as cardiosphere-derived cells (CDCs) (88). Preclinical studies, which evaluated beneficial effects in dystrophic heart as the primary outcome, demonstrated that CDCs delivered systemically in $m d x$ mice improved also the skeletal muscle phenotype $(89,90)$. However, these effects appeared to be due not to genetic restoration of dystrophin, but rather to effects possibly related to exosomes secreted by the transplanted cells. Intriguingly, in a clinical trial of the intracoronary injection of CDCs in 25 DMD patients, a measure of upper limb strength was greater in the 13 treated patients compared with the 12 controls (91). These findings have led to an additional clinical trial (NCT03406780) in which CDCs were injected intravenously in a cohort of mostly (80\%) nonambulatory DMD patients (Table 2).

Bone marrow-derived/blood-borne cells. Despite initial enthusiasm that bone marrow-derived hematopoietic cells might serve as a source of myogenic progenitors and that bone marrow transplantation could then be a treatment for muscular dystrophies (92, 93), long-term studies in which bone marrow transplantation was performed in $m d x$ mice found a negligible effect: only $0.09 \%$ of the myofibers became chimeric during the entire lifespan of the mice (94). These negative results were confirmed in a study performed in dystrophic dogs (95). Inefficient contribution of cells of the hematopoietic lineage into myofibers was also observed in DMD patients $(96,97)$.

The inefficiency of bone marrow cells in complementing dystrophin expression in dystrophic patients led to a search for alternative sources of circulating myogenic progenitors. A population of cells expressing CD133 and exhibiting myogenic poten- 
tial when cocultured with myogenic cells was identified in the blood and muscle of DMD patients $(98,99)$. CD133 ${ }^{+}$cells were shown to ameliorate the dystrophic phenotype upon transplantation in different dystrophic mouse strains (98-100). Intramuscular and intra-arterial delivery of genetically corrected CD133 cells, isolated from DMD patients and transduced with lentiviral vectors expressing antisense oligonucleotides with exon-skipping ability, resulted in dystrophin expression and a recovery of muscle function in $m d x / S C I D$ mice (99). Similarly corrected, autologous, muscle-derived $\mathrm{CD} 133^{+}$cells were shown to increase the number of dystrophin-positive fibers when injected intra-arterially in GRMD dogs (101).

\section{Pluripotent stem cells}

Pluripotent stem cells (PSCs), comprising embryonic stem cells (ESCs) and induced pluripotent stem cells (iPSCs), are particularly appealing in regenerative medicine because they can be propagated indefinitely in the undifferentiated state but retain the capacity to differentiate to all somatic tissues $(102,103)$. Protocols to obtain muscle progenitors from PSCs are creating possibilities for cell therapy for DMD (104).

Initial studies aimed at the generation of myogenic progenitors involved the formation of embryonic bodies (EBs) and led to poor myogenic differentiation, which was attributed to spontaneous differentiation into heart progenitor cells (105). To increase differentiation along the skeletal myogenic lineage, forced overexpression of the transcription factor MyoD was attempted, but the resulting increase in differentiation remained suboptimal and failed to produce myogenic selfrenewing cells (106). Strategies relying on antibodies recognizing myogenic and mesenchymal markers and selective media compositions were used to isolate a minority of engraftable myogenic progenitors appearing in ESC cultures $(107,108)$. Notably, generation of mouse myogenic precursors endowed with in vivo regenerative potential was also achieved by the expressing of a central regulator of embryonic myogenesis, PAX3, during EB-PSC differentiation (109). Similar approaches based on overexpression of PAX7 were subsequently used to generate human skeletal myogenic precursors from both ESCs and iPSCs $(110,111)$. These PSC-derived myogenic progenitors were shown to promote substantial muscle regeneration and to seed the MuSC compartment when delivered systemically or intramuscularly to $m d x$ mice $(109,110,112,113)$.

As an alternative to transcription factor transfection, directed differentiation of PSCs to form myogenic progenitors has met with success. The first study to reprogram, differentiate, genetically correct, and transplant human iPSC-derived myogenic cells from patients with muscular dystrophy involved the differentiation of cells toward MAB-like cells (114). Human and mouse myogenic progenitors have been generated from PSCs by the inclusion of factors important for muscle development in the medium (115, 116). Notably, those culture conditions resulted in production of $\mathrm{PAX}^{+}$cells resembling quiescent MuSCs. When transplanted in vivo in a preclinical model of DMD, the myogenic cells form large foci of myofibers (115).

It was also demonstrated that genetically corrected DMD myogenic cells derived from human PSCs (hPSCs; using CRISPR/
Cas9 technology) could be directed to differentiate and restore dystrophin in immune-deficient $m d x$ mice to levels approaching those observed in cells directly isolated from fetal tissues (117, 118). Work from different laboratories further expanded both gene correction strategies and myogenic cell induction/selection protocols applied to PSCs $(111,119-122)$.

Notably, a recent study reported the production of myogenic progenitors from teratomas derived from murine PSCs (123). This protocol relies on isolation of myogenic progenitors from teratomas developed from PSCs injected in injured dystrophic muscle. Importantly, the ability to colonize host muscle after intramuscular injection appears to be greater in teratomaderived cells than in myoblasts and PAX-modified PSCs. Teratoma-derived cells can also give rise to functional MuSCs (123). Further studies will address whether teratoma-derived myogenic cells are suitable for systemic delivery and whether they can be derived from human teratomas.

Direct reprogramming to myogenic progenitors. Protocols involving overexpression of myogenic regulatory factors have been proposed to efficiently derive myogenic progenitors from sources different from PSCs, in a process of direct reprogramming that is applicable to fibroblasts from DMD patients (124). This approach was used to generate myogenic progenitors for testing in transplantation paradigms in $m d x$ mice (125). Direct reprogramming of accessible autologous cell types may represent a clinically relevant alternative to PSC-derived cells.

\section{Cell therapy in dystrophic heart}

Over the past two decades, more than 200 trials based on cell transplantation have been performed in patients affected by cardiovascular diseases. These trials have involved different cell types, such as skeletal myoblasts, bone marrow-derived cells, MSCs, and cardiac-resident progenitors (126). However, the efficacy of these cells remains controversial, and the absence of a general consensus has limited the transition of these therapies from investigational to general practice (127). In particular, the poor ability to differentiate into cardiomyocytes and the resulting risks of promoting ventricular arrhythmias are limiting the application of myoblast transplantation (128).

The ideal cell type to use in DMD heart would generate new cardiomyocytes expressing dystrophin, which would confer long-term protection against the disease process. Similar to what has been reported for skeletal muscle, restoring 15\%-20\% of normal levels of dystrophin appears to be sufficient to prevent cardiac disease progression (129). Preclinical studies in dystrophic mice have investigated the cardiac effects of cells that had previously been tested in skeletal muscle. Bone marrow transplantations in $m d x$ mice suggest a limited contribution of bone marrow-derived cells to the cardiomyocyte pool (92). Aorta-derived MABs, which can be induced to differentiate into beating cardiomyocytes in vitro, can delay the onset of cardiomyopathy upon transplantation into the hearts of severely dystrophic mice $(53,130)$. Intriguingly, a population of MABs, able to spontaneously differentiate into functional cardiomyocytes and referred to as cardiac MABs, was isolated from ventricles of postnatal hearts (131). Although not yet tested in dystrophic settings, cardiac MABs efficiently generate new myocardium 


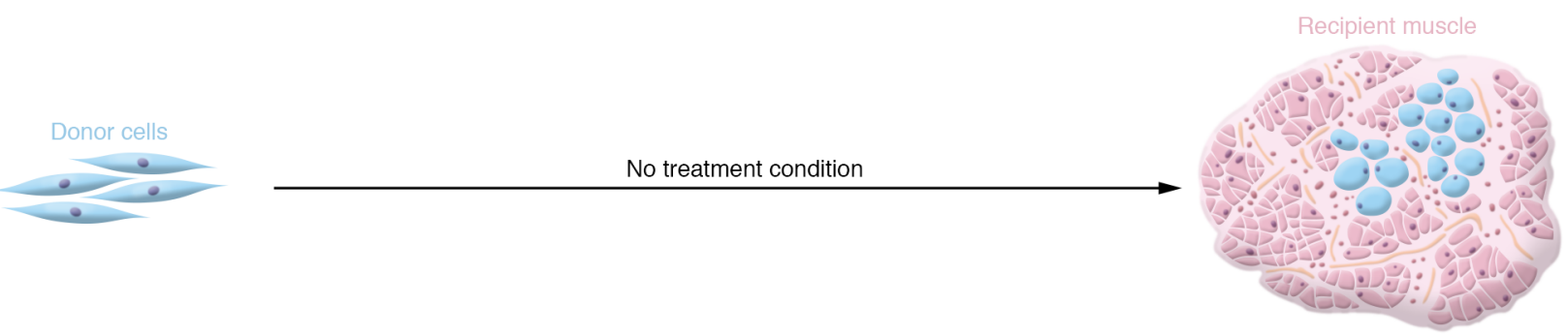

B
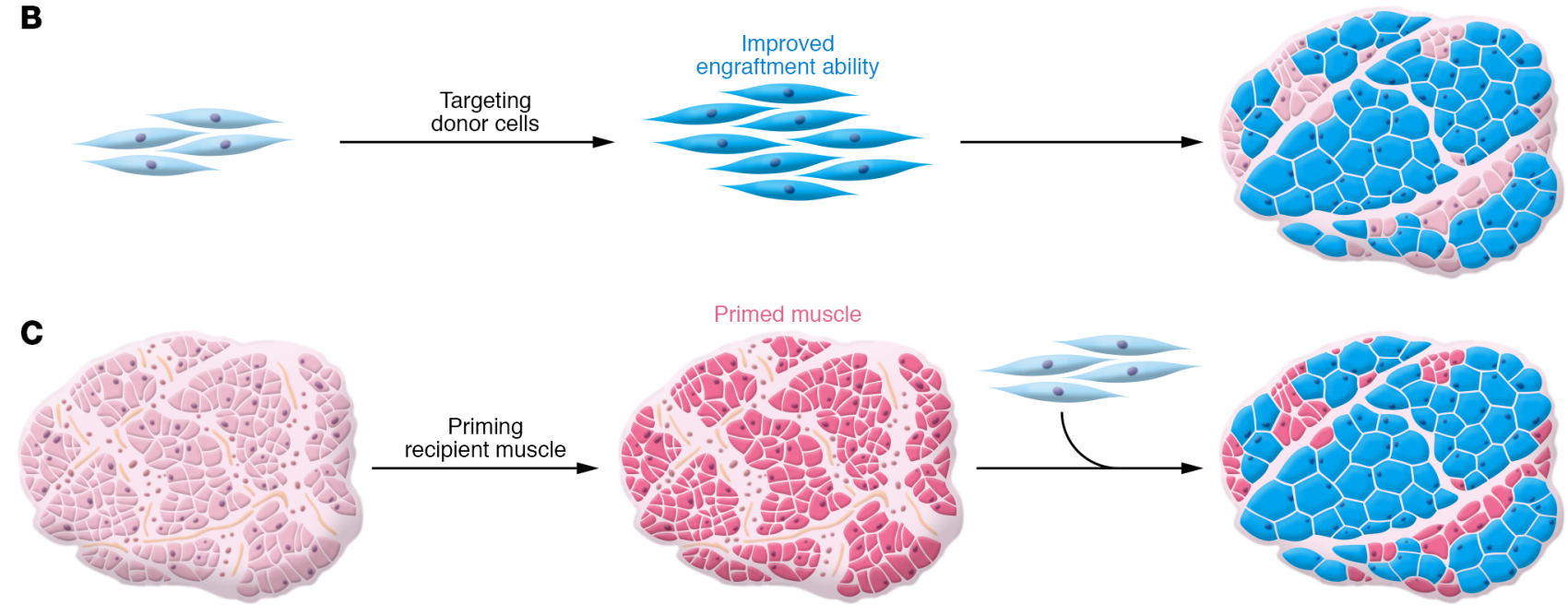

Figure 3. Strategies aimed at increasing in vivo engraftment of transplanted cells. (A-C) Approaches to enhance productive engraftment in cell transplantation experiments include targeting the cells to be transplanted and priming the recipient tissue. Productive engraftment is schematized by a transverse section of a transplanted muscle showing an increased proportion of fibers replenished by the transplanted cells (marked as blue fibers) compared with "No treatment condition," as well as a reduction in the dystrophic pathology.

in ischemic murine hearts (131). More recently, the observation that iPSCs may be obtained from DMD patients, genetically corrected, and differentiated to functional cardiomyocytes has paved the way for future investigations for the treatment of dystrophic cardiomyopathy (117). Finally, CDCs were shown to improve cardiac myopathy after intra-cardiac or intravenous delivery in $m d x$ mice $(89,90)$.

Recently, a phase I/II randomized, controlled, open-label trial (NCT02485938) assessed the safety and efficacy of intracoronary allogenic CDCs in DMD patients with established cardiomyopathy (91). CDC administration appeared safe and demonstrated signs of efficacy. The sustained changes in scar and regional function are reminiscent of the responses to CDC observed in a recent trial of ischemic cardiomyopathy (132). The results of a recently completed follow-up phase II double-blind, placebo-controlled clinical trial (NCT03406780), in which CDCs were infused intravenously, await publication.

\section{Challenges and future perspective}

To date, only MuSC-derived myoblasts, MABs, CD133 ${ }^{+}$cells, MSCs, and CDCs have been evaluated in clinical trials, and only in studies involving a limited number of dystrophic patients (Table 1 and Table 2). Despite some positive indications in terms of safety or functional/histological recovery, these therapeutic options are still preliminary. Many obstacles continue to limit the clinical use of cell therapy in dystrophic settings.
An important limitation is that MuSCs lose their regenerative potential when expanded ex vivo $(35,133)$. Similarly, CD133 ${ }^{+}$cells, SP cells, and MABs appear to be defective when isolated from diseased muscles (134-136). Since the first pioneering studies on myoblast transplantation, there has been much interest in developing culturing conditions to preserve the regenerative potential of transplanted cells (45). Most studies were initially centered on myoblasts and MuSCs, but findings can potentially be extended also to other cell types (Figure 2). A promising approach uses bioengineering principles to more closely mimic, in terms of tissue rigidity, the natural microenvironment, where MuSCs are maintained $(137,138)$. Alternative approaches rely on modulation of signaling pathways that maintain stemness and suppress terminal myogenic differentiation $(35,139-143)$. Additionally, epigenetic regulators have been studied as potential ways to enhance the therapeutic potential of MuSCs (144). Genetic manipulation was also shown to be a suitable approach, as exemplified in a study in which reversible cell immortalization was obtained with excisable hTERT and Bmi1 transgenes, in both DMD MuSCs and MABs (145). Additionally, different reports suggest that interfering with genes controlling the myogenic program may preserve muscle cell regenerative potential $(146,147)$. Finally, lowering oxygen tension close to physiological levels was shown to improve the self-renewal of myoblasts and transplantation efficiency in $m d x$ mice (148).

Poor engraftment is another obstacle hindering the success of cell transplantation approaches, which depend on different 
parameters such as homing to the degenerating skeletal muscle, intramuscular diffusion, survival, and proper functional maturation of the transplanted cells. Attempts have been made to modulate key molecular determinants controlling these parameters (Figure 3). The amount of donor muscle formed reportedly increased after exposure of donor myogenic cells, before or during their implantation, to factors altering the activity of signaling pathways initiated by FGF, IGF, IL-4, Wnt7a, and TGF- $\beta$ superfamily members (149-153). Other approaches attempted to increase the survival of grafted cells by preconditioning cells with stressful stimuli or interfering with signaling pathways controlling cell death $(154,155)$. Several injectable biomaterials have also been shown to improve survival and the maturation of cells transplanted in dystrophic muscles $(156,157)$.

Several strategies targeting the recipient tissues reportedly increase engraftment (Figure 3). Exercise or induction of mild local damage was shown to improve transplantation efficiency of different cell types (158-160). Promoting neovascularization enhances engraftment of myoblasts, MABs, and MDSCs (161-163). Modifying extracellular matrix or inhibiting profibrotic molecules improves muscle engraftment (161, 164-167). The inflammatory state of recipient muscles also seems to play a key role in controlling transplantation outcome, as intramuscular coinjection of macrophages with myoblasts enhanced their engraftment (168). Moreover, intramuscular overexpression of the cytokine HMGB1 and the antiinflammatory action of a nitric oxide-releasing derivative of flurbiprofen increase the efficacy of MAB therapy $(169,170)$.

One of the greatest challenges for cell therapy in muscular dystrophies is effective systemic delivery. The selection of a proper route of administration appears to be crucial. Arterial delivery seems to be an absolute requirement to escape filter organs, which are likely to prevent any intravenously delivered cells from reaching muscles throughout the body, and to ensure muscle targeting with consequent genetic complementation $(54,171)$. Another important aspect influencing the outcome of systemic delivery is the ability of the transplanted cells to cross the blood vessels and colonize the recipient muscles. Notably, promising attempts were recently made to enhance transendothelial migratory ability in MuSC-derived myoblasts (172). Furthermore, specific molecules have been shown to modulate the muscle homing of systemically injected CD $133^{+}$cells, MDSCs, SP cells, and MABs (159, 173-175). These initial studies call for a systematic investigation of the molecular and cellular events controlling these processes.

An additional determinant of productive cell therapy is the control of the immune response against transplanted allogenic cells or against autologous cells expressing a foreign therapeutic gene (176). The exact mechanisms underlying rejection are still under active investigation, but increasing evidence suggests a major role for $\mathrm{T}$ lymphocytes $(101,177,178)$. The optimization of protocols to minimize the immune response will be crucial for the success of cell therapy in dystrophies and will require careful evaluation of the immunogenic properties of the specific cell population to be transplanted $(44,81,84,179)$, selection of effective immunosuppressant drugs that are not toxic to the transplanted cells $(180,181)$, and identification of the optimal dosage and duration of immunosuppression to balance efficacy and undesired side effects. Indeed, evidence suggests that transient immunosuppression might be sufficient to ensure the long-term retention of transplanted cells $(182,183)$.

For most of the cell populations that have been tested, the relative contribution of paracrine effects versus gene complementation is unknown. An understanding of these issues will facilitate the definition of effective cell therapy protocols. The experience gained with recent preclinical and clinical studies will lead to improved clinical trial design (184). These optimizations, together with the recent progress in gene correction strategies, will pave the road for future evaluation of cell therapy in muscle diseases.

\section{Acknowledgments}

We thank Cindy van Velthoven for the generation of the figures, and Giulio Cossu for stimulating discussions. Work in the authors' laboratories is supported by Telethon and Provincia autonoma di Trento, Italy (grant TCP13007), to SB and by grants from the NIH (AG036695, AR073248) and the Department of Veterans Affairs (I01RX001222, I01BX002324) to TAR.

Address correspondence to: Thomas A. Rando, Department of Neurology and Neurological Sciences, Stanford University School of Medicine, Stanford, California 94305-5235, USA. Phone 650.849.0444; Email: rando@stanford.edu. Or to:Stefano Biressi, Department of Cellular, Computational and Integrative Biology, University of Trento, Via Sommarive 9, Povo, 38123 Trento, Italy. Phone: 39.0461.28.5290; Email: stefano.biressi@unitn.it.
1. Emery AE. The muscular dystrophies. Lancet. 2002;359(9307):687-695.

2. Mercuri E, Bönnemann CG, Muntoni F. Muscular dystrophies. Lancet. 2019;394(10213):20252038.

3. Mercuri E, Muntoni F. Muscular dystrophies. Lancet. 2013;381(9869):845-860.

4. Nigro V, Piluso G. Spectrum of muscular dystrophies associated with sarcolemmalprotein genetic defects. Biochim Biophys Acta. 2015;1852(4):585-593.

5. Hermans MCE, et al. Hereditary muscular dystrophies and the heart. Neuromuscul Disord. 2010;20(8):479-492.

6. Nigro G, Comi LI, Politano L, Bain RJI. The incidence and evolution of cardiomyopathy in Duchenne muscular dystrophy. Int J Cardiol. 1990;26(3):271-277.

7. Connuck DM, et al. Characteristics and outcomes of cardiomyopathy in children with Duchenne or Becker muscular dystrophy: a comparative study from the Pediatric Cardiomyopathy Registry. Am Heart J. 2008;155(6):998-1005.

8. Hoffman EP, Brown RH, Kunkel LM. Dystrophin: the protein product of the Duchenne muscular dystrophy locus. Cell. 1987;51(6):919-928.

9. Koenig M, et al. The molecular basis for Duchenne versus Becker muscular dystrophy: correlation of severity with type of deletion. Am J Hum Genet. 1989;45(4):498-506.
10. Ervasti JM, Campbell KP. A role for the dystrophin-glycoprotein complex as a transmembrane linker between laminin and actin. JCell Biol. 1993;122(4):809-823.

11. Schmalbruch H. Segmental fibre breakdown and defects of the plasmalemma in diseased human muscles. Acta Neuropathol. 1975;33(2):129-141.

12. Carpenter S, Karpati G. Duchenne muscular dystrophy: plasma membrane loss initiates muscle cell necrosis unless it is repaired. Brain. 1979;102(1):147-161.

13. Rando TA. The dystrophin-glycoprotein complex, cellular signaling, and the regulation of cell survival in the muscular dystrophies. Muscle Nerve. 2001;24(12):1575-1594. 
14. Allen DG, Whitehead NP, Froehner SC. Absence of dystrophin disrupts skeletal muscle signaling: roles of $\mathrm{Ca} 2+$, reactive oxygen species, and nitric oxide in the development of muscular dystrophy. Physiol Rev. 2016;96(1):253-305.

15. Rosenberg AS, et al. Immune-mediated pathology in Duchenne muscular dystrophy. Sci Transl Med. 2015;7(299):299rv4.

16. McDonald CM, et al. Long-term effects of glucocorticoids on function, quality of life, and survival in patients with Duchenne muscular dystrophy: a prospective cohort study. Lancet. 2018;391(10119):451-461.

17. Birnkrant DJ, et al. Diagnosis and management of Duchenne muscular dystrophy, part 2: respiratory, cardiac, bone health, and orthopaedic management. Lancet Neurol. 2018;17(4):347-361.

18. Bengtsson NE, Seto JT, Hall JK, Chamberlain JS, Odom GL. Progress and prospects of gene therapy clinical trials for the muscular dystrophies. Hum Mol Genet. 2016;25(R1):R9-R17.

19. Verhaart IEC, Aartsma-Rus A. Therapeutic developments for Duchenne muscular dystrophy. Nat Rev Neurol. 2019;15(7):373-386.

20. Nelson CE, Robinson-Hamm JN, Gersbach CA. Genome engineering: a new approach to gene therapy for neuromuscular disorders. Nat Rev Neurol. 2017;13(11):647-661.

21. Miura P, Jasmin BJ. Utrophin upregulation for treating Duchenne or Becker muscular dystrophy: how close are we? Trends Mol Med. 2006;12(3):122-129.

22. Guiraud S, Davies KE. Pharmacological advances for treatment in Duchenne muscular dystrophy. Curr Opin Pharmacol. 2017;34:36-48.

23. Ichim TE, et al. Mesenchymal stem cells as anti-inflammatories: implications for treatment of Duchenne muscular dystrophy. Cell Immunol. 2010;260(2):75-82.

24. Sambasivan R, Tajbakhsh S. Adult skeletal muscle stem cells. In: Kubiac JZ, Kloc M, eds. Results and Problems in Cell Differentiation. Springer; 2015:191-213.

25. Scharner J, Zammit PS. The muscle satellite cell at 50: the formative years. Skelet Muscle. 2011;1(1):28.

26. Lepper C, Partridge TA, Fan CM. An absolute requirement for Pax7-positive satellite cells in acute injury-induced skeletal muscle regeneration. Development. 2011;138(17):3639-3646.

27. Murphy MM, Lawson JA, Mathew SJ, Hutcheson DA, Kardon G. Satellite cells, connective tissue fibroblasts and their interactions are crucial for muscle regeneration. Development. 2011;138(17):3625-3637.

28. Sambasivan R, et al. Pax7-expressing satellite cells are indispensable for adult skeletal muscle regeneration. Development. 2011;138(17):3647-3656.

29. Cheung TH, Rando TA. Molecular regulation of stem cell quiescence. Nat Rev Mol Cell Biol. 2013;14(6):329-340.

30. Zammit PS, et al. Muscle satellite cells adopt divergent fates: a mechanism for self-renewal? JCell Biol. 2004;166(3):347-357.

31. Sacco A, Doyonnas R, Kraft P, Vitorovic S, Blau HM. Self-renewal and expansion of single transplanted muscle stem cells. Nature. 2008;456(7221):502-506.
32. Collins CA, et al. Stem cell function, selfrenewal, and behavioral heterogeneity of cells from the adult muscle satellite cell niche. Cell. 2005;122(2):289-301.

33. Marg A, et al. Human satellite cells have regenerative capacity and are genetically manipulable. J Clin Invest. 2014;124(10):4257-4265.

34. Xu X, et al. Human satellite cell transplantation and regeneration from diverse skeletal muscles. Stem Cell Reports. 2015;5(3):419-434.

35. Charville GW, et al. Ex vivo expansion and in vivo self-renewal of human muscle stem cells. Stem Cell Reports. 2015;5(4):621-632.

36. Partridge TA, Morgan JE, Coulton GR, Hoffman EP, Kunkel LM. Conversion of mdx myofibres from dystrophin-negative to -positive by injection of normal myoblasts. Nature. 1989;337(6203):176-179.

37. Vilquin JT, et al. Partial laminin alpha 2 chain restoration in alpha 2 chain-deficient $\mathrm{dy} / \mathrm{dy}$ mouse by primary muscle cell culture transplantation. J Cell Biol. 1996;133(1):185-197.

38. Partridge TA. Invited review: Myoblast transfer: a possible therapy for inherited myopathies? Muscle Nerve. 1991;14(3):197-212.

39. Yao SN, Kurachi K. Implanted myoblasts not only fuse with myofibers but also survive as muscle precursor cells. J Cell Sci. 1993;105(pt 4):957-963.

40. Partridge T. Myoblast transplantation. Neuromus cul Disord. 2002;12(suppl 1):S3-S6.

41. Mendell JR, et al. Myoblast transfer in the treatment of Duchenne's muscular dystrophy. N Engl J Med.1995;333(13):832-838.

42. Gussoni E, et al. Normal dystrophin transcripts detected in Duchenne muscular dystrophy patients after myoblast transplantation. Nature. 1992;356(6368):435-438.

43. Karpati G, et al. Myoblast transfer in Duchenne muscular dystrophy. Ann Neurol. 1993;34(1):8-17.

44. Tremblay JP, et al. Results of a triple blind clinical study of myoblast transplantations without immunosuppressive treatment in young boys with Duchenne muscular dystrophy. Cell Transplant. 1993;2(2):99-112.

45. Briggs D, Morgan JE. Recent progress in satellite cell/myoblast engraftment - relevance for therapy. FEBS J. 2013;280(17):4281-4293.

46. Ito $\mathrm{H}$, et al. Myoblast transplantation in nondystrophic dog. Neuromuscul Disord. 1998;8(2):95-110.

47. Skuk D, Goulet M, Roy B, Tremblay JP. Myoblast transplantation in whole muscle of nonhuman primates. J Neuropathol Exp Neurol. 2000;59(3):197-206.

48. Skuk D, et al. Dystrophin expression in muscles of duchenne muscular dystrophy patients after high-density injections of normal myogenic cells. J Neuropathol Exp Neurol. 2006;65(4):371-386.

49. Skuk D, et al. First test of a "high-density injection" protocol for myogenic cell transplantation throughout large volumes of muscles in a Duchenne muscular dystrophy patient: eighteen months follow-up. Neuromuscul Disord. 2007;17(1):38-46

50. Skuk D, Goulet M, Tremblay JP. Intramuscular transplantation of myogenic cells in primates: importance of needle size, cell number, and injection volume. Cell Transplant. 2014;23(1):13-25.
51. Périé S, et al. Autologous myoblast transplantation for oculopharyngeal muscular dystrophy: a phase I/IIa clinical study. Mol Ther. 2014;22(1):219-225.

52. Skuk D, Tremblay JP. First study of intraarterial delivery of myogenic mononuclear cells to skeletal muscles in primates. Cell Transplant. 2014;23(suppl 1):S141-S150.

53. Minasi MG, et al. The meso-angioblast: a multipotent, self-renewing cell that originates from the dorsal aorta and differentiates into most mesodermal tissues. Development. 2002;129(11):2773-2783.

54. Sampaolesi M, et al. Cell therapy of alphasarcoglycan null dystrophic mice through intra-arterial delivery of mesoangioblasts. Science. 2003;301(5632):487-492.

55. Dellavalle A, et al. Pericytes of human skeletal muscle are myogenic precursors distinct from satellite cells. Nat Cell Biol. 2007;9(3):255-267.

56. Sampaolesi M, et al. Mesoangioblast stem cells ameliorate muscle function in dystrophic dogs. Nature. 2006;444(7119):574-579.

57. Berry SE, Liu J, Chaney EJ, Kaufman SJ. Multipotential mesoangioblast stem cell therapy in the mdx/utrn-/- mouse model for Duchenne muscular dystrophy. Regen Med. 2007;2(3):275-288.

58. Díaz-Manera J, et al. Partial dysferlin reconstitution by adult murine mesoangioblasts is sufficient for full functional recovery in a murine model of dysferlinopathy. Cell Death Dis. 2010;1(8):e61.

59. Tedesco FS, et al. Stem cell-mediated transfer of a human artificial chromosome ameliorates muscular dystrophy. Sci Transl Med. 2011;3(96):96ra78.

60. English K, Tonlorenzi R, Cossu G, Wood KJ. Mesoangioblasts suppress $\mathrm{T}$ cell proliferation through IDO and PGE-2-dependent pathways. Stem Cells Dev. 2013;22(3):512-523.

61. Dellavalle A, et al. Pericytes resident in postnatal skeletal muscle differentiate into muscle fibres and generate satellite cells. Nat Commun. 2011;2:499.

62. Cossu G, et al. Intra-arterial transplantation of HLA-matched donor mesoangioblasts in Duchenne muscular dystrophy. EMBO Mol Med. 2015;7(12):1513-1528.

63. Péault B, et al. Stem and progenitor cells in skeletal muscle development, maintenance, and therapy. Mol Ther. 2007;15(5):867-877.

64. Gussoni E, et al. Dystrophin expression in the mdx mouse restored by stem cell transplantation. Nature. 1999;401(6751):390-394.

65. Camargo FD, et al. Single hematopoietic stem cells generate skeletal muscle through myeloid intermediates. Nat Med. 2003;9(12):1520-1527.

66. Muskiewicz KR, Frank NY, Flint AF, Gussoni E. Myogenic potential of muscle side and main population cells after intravenous injection into sub-lethally irradiated mdx mice.J Histochem Cytochem. 2005;53(7):861-873.

67. Bachrach E, et al. Muscle engraftment of myogenic progenitor cells following intraarterial transplantation. Muscle Nerve. 2006;34(1):44-52

68. Frank NY, et al. Regulation of myogenic progenitor proliferation in human fetal skeletal muscle by BMP4 and its antagonist Gremlin. JCell Biol. 
2006;175(1):99-110.

69. Mitchell KJ, et al. Identification and characterization of a non-satellite cell muscle resident progenitor during postnatal development. Nat Cell Biol. 2010;12(3):257-266.

70. Pisani DF, et al. Hierarchization of myogenic and adipogenic progenitors within human skeletal muscle. Stem Cells. 2010;28(12):2182-2194.

71. Qu-Petersen Z, et al. Identification of a novel population of muscle stem cells in mice: potential for muscle regeneration. J Cell Biol. 2002;157(5):851-864.

72. Rouger K, et al. Systemic delivery of allogenic muscle stem cells induces long-term muscle repair and clinical efficacy in duchenne muscular dystrophy dogs. Am J Pathol. 2011;179(5):2501-2518.

73. Vauchez K, et al. Aldehyde dehydrogenase activity identifies a population of human skeletal muscle cells with high myogenic capacities. Mol Ther. 2009;17(11):1948-1958.

74. Giordani L, et al. High-dimensional single-cell cartography reveals novel skeletal muscle-resident cell populations. Mol Cell. 2019;74(3):609-621.e6.

75. Martin I, Galipeau J, Kessler C, Le Blanc K, Dazzi F. Challenges for mesenchymal stromal cell therapies. Sci Transl Med. 2019;11(480):eaat2189.

76. De Bari C, Dell'Accio F, Vandenabeele F, Vermeesch JR, Raymackers JM, Luyten FP. Skeletal muscle repair by adult human mesenchymal stem cells from synovial membrane. J Cell Biol. 2003;160(6):909-918.

77. Rodriguez A-M, et al. Transplantation of a multipotent cell population from human adipose tissue induces dystrophin expression in the immunocompetent mdx mouse. J Exp Med. 2005;201(9):1397-1405.

78. Chan J, et al. Widespread distribution and muscle differentiation of human fetal mesenchymal stem cells after intrauterine transplantation in dystrophic mdx mouse. Stem Cells. 2007;25(4):875-884.

79. Liu Y, et al. Flk-1+ adipose-derived mesenchymal stem cells differentiate into skeletal muscle satellite cells and ameliorate muscular dystrophy in mdx mice. Stem Cells Dev. 2007;16(5):695-706.

80. Feng SW, et al. Dynamic distribution of bone marrow-derived mesenchymal stromal cells and change of pathology after infusing into $\mathrm{mdx}$ mice. Cytotherapy. 2008;10(3):254-264.

81. Shabbir A, et al. Muscular dystrophy therapy by nonautologous mesenchymal stem cells: muscle regeneration without immunosuppression and inflammation. Transplantation. 2009;87(9):1275-1282.

82. Gang EJ, et al. Engraftment of mesenchymal stem cells into dystrophin-deficient mice is not accompanied by functional recovery. Exp Cell Res. 2009;315(15):2624-2636.

83. Griffin MD, Ritter T, Mahon BP. Immunological aspects of allogeneic mesenchymal stem cell therapies. Hum Gene Ther. 2010;21(12):1641-1655.

84. Vieira NM, et al. Human adipose-derived mesenchymal stromal cells injected systemically into GRMD dogs without immunosuppression are able to reach the host muscle and express human dystrophin. Cell Transplant. 2012;21(7):1407-1417.

85. Kerkis I, et al. Early transplantation of human immature dental pulp stem cells from baby teeth to golden retriever muscular dystrophy (GRMD) dogs: local or systemic? J Transl Med. 2008;6:35.

86. Li P, et al. Transplantation of human umbilical cord-derived mesenchymal stems cells for the treatment of Becker muscular dystrophy in affected pedigree members. Int J Mol Med. 2015;35(4):1051-1057.

87. Dai A, et al. Efficacy of stem cell therapy in ambulatory and nonambulatory children with Duchenne muscular dystrophy - Phase I-II. Degener Neurol Neuromuscul Dis. 2018;8:63-77.

88. Marbán E. Breakthroughs in cell therapy for heart disease: focus on cardiosphere-derived cells. Mayo Clin Proc. 2014;89(6):850-858.

89. Aminzadeh MA, et al. Exosome-mediated benefits of cell therapy in mouse and human models of Duchenne muscular dystrophy. Stem Cell Reports. 2018;10(3):942-955.

90. Rogers RG, et al. Disease-modifying bioactivity of intravenous cardiosphere-derived cells and exosomes in mdx mice. JCI Insight. 2019;4(7):125754

91. Taylor M, et al. Cardiac and skeletal muscle effects in the randomized HOPE-Duchenne trial. Neurology. 2019;92(8):e866-e878.

92. Bittner RE, et al. Recruitment of bone-marrowderived cells by skeletal and cardiac muscle in adult dystrophic mdx mice. Anat Embryol (Berl). 1999;199(5):391-396.

93. Ferrari G, et al. Muscle regeneration by bone marrow-derived myogenic progenitors. Science. 1998;279(5356):1528-1530.

94. Ferrari G, Stornaiuolo A, Mavilio F. Failure to correct murine muscular dystrophy. Nature. 2001;411(6841):1014-1015.

95. Dell'Agnola C, et al. Hematopoietic stem cell transplantation does not restore dystrophin expression in Duchenne muscular dystrophy dogs. Blood. 2004;104(13):4311-4318.

96. Gussoni E, et al. Long-term persistence of donor nuclei in a Duchenne muscular dystrophy patien receiving bone marrow transplantation. J Clin Invest. 2002;110(6):807-814.

97. Kang PB, et al. Inefficient dystrophin expression after cord blood transplantation in Duchenne muscular dystrophy. Muscle Nerve. 2010;41(6):746-750.

98. Torrente Y, et al. Human circulating AC133(+) stem cells restore dystrophin expression and ameliorate function in dystrophic skeletal muscle. J Clin Invest. 2004;114(2):182-195.

99. Benchaouir R, et al. Restoration of human dystrophin following transplantation of exon-skipping-engineered DMD patient stem cells into dystrophic mice. Cell Stem Cell. 2007;1(6):646657.

100.Meregalli M, et al. Full-length dysferlin expression driven by engineered human dystrophic blood derived CD133+ stem cells. FEBS J. 2013;280(23):6045-6060.

101.Sitzia C, et al. Adaptive immune response impairs the efficacy of autologous transplantation of engineered stem cells in dystrophic dogs. $\mathrm{Mol}$ Ther. 2016;24(11):1949-1964.

102. Evans MJ, Kaufman MH. Establishment in culture of pluripotential cells from mouse embryos. Nature. 1981;292(5819):154-156.

103. Takahashi K, Yamanaka S. Induction of plurip- otent stem cells from mouse embryonic and adult fibroblast cultures by defined factors. Cell. 2006;126(4):663-676.

104.Pourquié O, Al Tanoury Z, Chal J. The long road to making muscle in vitro. Curr Top Dev Biol. 2018;129:123-142.

105. Robbins J, Gulick J, Sanchez A, Howles P, Doetschman T. Mouse embryonic stem cells express the cardiac myosin heavy chain genes during development in vitro. J Biol Chem. 1990;265(20):11905-11909.

106.Dekel I, Magal Y, Pearson-White S, Emerson CP, Shani M. Conditional conversion of ES cells to skeletal muscle by an exogenous MyoD1 gene. New Biol. 1992;4(3):217-224.

107. Barberi T, et al. Derivation of engraftable skeletal myoblasts from human embryonic stem cells. Nat Med. 2007;13(5):642-648.

108. Chang H, et al. Generation of transplantable, functional satellite-like cells from mouse embryonic stem cells. FASEB J. 2009;23(6):1907-1919.

109. Darabi R, et al. Functional skeletal muscle regeneration from differentiating embryonic stem cells. Nat Med. 2008;14(2):134-143.

110. Darabi R, et al. Human ES- and iPS-derived myogenic progenitors restore DYSTROPHIN and improve contractility upon transplantation in dystrophic mice. Cell Stem Cell. 2012;10(5):610-619.

111. Magli A, et al. PAX7 targets, CD54, integrin $\alpha 9 \beta 1$, and SDC2, allow isolation of human ESC/ iPSC-derived myogenic progenitors. Cell Rep. 2017;19(13):2867-2877.

112. Darabi R, et al. Assessment of the myogenic stem cell compartment following transplantation of Pax3/Pax7-induced embryonic stem cell-derived progenitors. Stem Cells. 2011;29(5):777-790.

113. Filareto A, Darabi R, Perlingeiro RCR. Engraftment of ES-derived myogenic progenitors in a severe mouse model of muscular dystrophy. J Stem Cell Res Ther. 2012;10(1):S10-001.

114. Tedesco FS, et al. Transplantation of genetically corrected human iPSC-derived progenitors in mice with limb-girdle muscular dystrophy. Sci Transl Med. 2012;4(140):140ra89.

115. Chal J, et al. Differentiation of pluripotent stem cells to muscle fiber to model Duchenne muscular dystrophy. Nat Biotechnol. 2015;33(9):962-969.

116. Chal J, et al. Generation of human muscle fibers and satellite-like cells from human pluripotent stem cells in vitro. Nat Protoc. 2016;11(10):1833-1850.

117. Young CSS, et al. A single CRISPR-Cas 9 deletion strategy that targets the majority of DMD patients restores dystrophin function in hiPSC-derived muscle cells. Cell Stem Cell. 2016;18(4):533-540.

118. Hicks MR, et al. ERBB3 and NGFR mark a distinct skeletal muscle progenitor cell in human development and hPSCs. Nat Cell Biol. 2018;20(1):46-57.

119. Sato T, et al. Core transcription factors promote induction of PAX3-positive skeletal muscle stem cells. Stem Cell Reports. 2019;13(2):352-365.

120. Selvaraj S, et al. Screening identifies small molecules that enhance the maturation of human pluripotent stem cell-derived myotubes. Elife. 2019;8:e47970.

121. Gee P, et al. Extracellular nanovesicles for pack- 
aging of CRISPR-Cas9 protein and sgRNA to induce therapeutic exon skipping. Nat Commun. 2020;11(1):1334

122.Sakai-Takemura F, et al. Premyogenic progenitors derived from human pluripotent stem cells expand in floating culture and differentiate into transplantable myogenic progenitors. Sci Rep. 2018;8(1):6555.

123. Chan SS, et al. Skeletal muscle stem cells from PSC-derived teratomas have functional regenerative capacity. Cell Stem Cell. 2018;23(1):74-85.e6.

124. Lee JJA, Saito T, Duddy W, Takeda S, Yokota T. Direct reprogramming of human DMD fibroblasts into myotubes for in vitro evaluation of antisense-mediated exon skipping and exons 45-55 skipping accompanied by rescue of dystrophin expression. Methods Mol Biol. 2018;1828:141-150.

125. Bar-Nur O, et al. Direct reprogramming of mouse fibroblasts into functional skeletal muscle progenitors. Stem Cell Reports. 2018;10(5):1505-1521.

126. Banerjee MN, Bolli R, Hare JM. Clinical studies of cell therapy in cardiovascular medicine: recent developments and future directions. Circ Res. 2018;123(2):266-287.

127. Chien KR, et al. Regenerating the field of cardiovascular cell therapy. Nat Biotechnol. 2019;37(3):232-237.

128. Coppen SR, et al. A factor underlying late-phase arrhythmogenicity after cell therapy to the heart: global downregulation of connexin 43 in the host myocardium after skeletal myoblast transplantation. Circulation. 2008;118(14 suppl):S138-S144.

129. Wells DJ. What is the level of dystrophin expression required for effective therapy of Duchenne muscular dystrophy? JMuscle Res Cell Motil. 2019;40(2):141-150.

130. Chun JL, O'Brien R, Song MH, Wondrasch BF, Berry SE. Injection of vessel-derived stem cells prevents dilated cardiomyopathy and promotes angiogenesis and endogenous cardiac stem cell proliferation in mdx/utrn-/- but not aged mdx mouse models for duchenne muscular dystrophy. Stem Cells Transl Med. 2013;2(1):68-80.

131. Galvez BG, et al. Cardiac mesoangioblasts are committed, self-renewable progenitors, associated with small vessels of juvenile mouse ventricle. Cell Death Differ. 2008;15(9):1417-1428.

132. Malliaras K, et al. Intracoronary cardiospherederived cells after myocardial infarction: evidence of therapeutic regeneration in the final 1-year results of the CADUCEUS trial (CArdiosphere-Derived aUtologous stem CElls to reverse ventricUlar dySfunction). JAm Coll Cardiol. 2014;63(2):110-122.

133. Montarras D, et al. Direct isolation of satellite cells for skeletal muscle regeneration. Science. 2005;309(5743):2064-2067.

134. Meng J, Muntoni F, Morgan J. CD133+ cells derived from skeletal muscles of Duchenne muscular dystrophy patients have a compromised myogenic and muscle regenerative capability. Stem Cell Res. 2018;30:43-52.

135. Penton CM, Thomas-Ahner JM, Johnson EK, McAllister C, Montanaro F. Muscle side population cells from dystrophic or injured muscle adopt a fibro-adipogenic fate. PLoS One. 2013;8(1):e54553.
136. Morosetti $\mathrm{R}$, et al. Isolation and characterization of mesoangioblasts from facioscapulohumeral muscular dystrophy muscle biopsies. Stem Cells. 2007;25(12):3173-3182.

137. Gilbert PM, et al. Substrate elasticity regulates skeletal muscle stem cell self-renewal in culture. Science. 2010;329(5995):1078-1081.

138. Quarta M, et al. An artificial niche preserves the quiescence of muscle stem cells and enhances their therapeutic efficacy. Nat Biotechnol. 2016;34(7):752-759.

139. Parker $\mathrm{MH}$, et al. Activation of Notch signaling during ex vivo expansion maintains donor muscle cell engraftment. Stem Cells. 2012;30(10):2212-2220.

140. Price FD, et al. Inhibition of JAK-STAT signaling stimulates adult satellite cell function. Nat Med. 2014;20(10):1174-1181.

141. Tierney MT, et al. STAT3 signaling controls satellite cell expansion and skeletal muscle repair. Nat Med. 2014;20(10):1182-1186.

142.Zismanov V, et al. Phosphorylation of eIF $2 \alpha$ is a translational control mechanism regulating muscle stem cell quiescence and self-renewal. Cell Stem Cell. 2016;18(1):79-90.

143. Sampath SC, et al. Induction of muscle stem cell quiescence by the secreted niche factor Oncostatin M. Nat Commun. 2018;9(1):1531.

144.Judson RN, et al. Inhibition of methyltransferase Setd7 allows the in vitro expansion of myogenic stem cells with improved therapeutic potential. Cell Stem Cell. 2018;22(2):177-190.e7.

145. Benedetti S, et al. Reversible immortalisation enables genetic correction of human muscle progenitors and engineering of next-generation human artificial chromosomes for Duchenne muscular dystrophy. EMBO Mol Med. 2018;10(2):254-275.

146.Asakura A, et al. Increased survival of muscle stem cells lacking the MyoD gene after transplantation into regenerating skeletal muscle. Proc Natl Acad Sci U S A . 2007;104(42):16552-16557.

147. Filareto A, et al. Pax3-induced expansion enables the genetic correction of dystrophic satellite cells. Skelet Muscle. 2015;5(1):36.

148. Liu W, et al. Hypoxia promotes satellite cell self-renewal and enhances the efficiency of myoblast transplantation. Development. 2012;139(16):2857-2865.

149. Bentzinger CF, et al. Wnt7a stimulates myogenic stem cell motility and engraftment resulting in improved muscle strength. JCell Biol. 2014;205(1):97-111.

150. Fakhfakh R, Lee SJ, Tremblay JP. Administration of a soluble activin type IIB receptor promotes the transplantation of human myoblasts in dystrophic mice. Cell Transplant. 2012;21(7):1419-1430.

151. Lafreniere JF, Mills P, Bouchentouf M, Tremblay JP. Interleukin- 4 improves the migration of human myogenic precursor cells in vitro and in vivo. Exp Cell Res. 2006;312(7):1127-1141.

152. Lafreniere JF, et al. Growth factor coinjection improves the migration potential of monkey myogenic precursors without affecting cell transplantation success. Cell Transplant. 2009;18(7):719-730.

153. Secco M, et al. Systemic delivery of human mesenchymal stromal cells combined with
IGF-1 enhances muscle functional recovery in LAMA2 dy/2j dystrophic mice. Stem Cell Rev Rep. 2013;9(1):93-109.

154. Gargioli C, et al. Oxidative stress preconditioning of mouse perivascular myogenic progenitors selects a subpopulation of cells with a distinct survival advantage in vitro and in vivo. Cell Death Dis. 2018;9(1):1.

155. Bouchentouf M, Benabdallah BF, Rousseau J, Schwartz LM, Tremblay JP. Induction of Anoikis following myoblast transplantation into SCID mouse muscles requires the Bit1 and FADD pathways. Am J Transplant. 2007;7(6):1491-1505.

156. Carnio S, et al. Three-dimensional porous scaffold allows long-term wild-type cell delivery in dystrophic muscle. J Tissue Eng Regen Med. 2011;5(1):1-10.

157. Fuoco C, et al. Injectable polyethylene glycolfibrinogen hydrogel adjuvant improves survival and differentiation of transplanted mesoangioblasts in acute and chronic skeletal-muscle degeneration. Skelet Muscle. 2012;2(1):24.

158. Skuk D, Goulet M, Tremblay JP. Electroporation as a method to induce myofiber regeneration and increase the engraftment of myogenic cells in skeletal muscles of primates. J Neuropathol Exp Neurol. 2013;72(8):723-734.

159. Gavina M, et al. VCAM-1 expression on dystrophic muscle vessels has a critical role in the recruitment of human blood-derived CD133+ stem cells after intra-arterial transplantation. Blood. 2006;108(8):2857-2866.

160. Bouchentouf M, Benabdallah BF, Mills P, Tremblay JP. Exercise improves the success of myoblast transplantation in mdx mice. Neuromuscul Disord. 2006;16(8):518-529.

161. Gargioli C, Coletta M, De Grandis F, Cannata SM, Cossu G. PlGF-MMP-9-expressing cells restore microcirculation and efficacy of cell therapy in aged dystrophic muscle. Nat Med. 2008;14(9):973-978.

162.Bouchentouf M, et al. Vascular endothelial growth factor reduced hypoxia-induced death of human myoblasts and improved their engraftment in mouse muscles. Gene Ther. 2008;15(6):404-414.

163. Deasy BM, et al. Effect of VEGF on the regenerative capacity of muscle stem cells in dystrophic skeletal muscle. Mol Ther. 2009;17(10):1788-1798.

164. Fakhfakh R, Lamarre Y, Skuk D, Tremblay JP. Losartan enhances the success of myoblast transplantation. Cell Transplant. 2012;21(1):139-152.

165. Morales MG, et al. Reducing CTGF/CCN2 slows down mdx muscle dystrophy and improves cell therapy. Hum Mol Genet. 2013;22(24):4938-4951.

166. Torrente Y, Fahime EE, Caron NJ, Bresolin $\mathrm{N}$, Tremblay JP. Intramuscular migration of myoblasts transplanted after muscle pretreatment with metalloproteinases. Cell Transplant. 2000;9(4):539-549.

167. Lee EM, et al. Therapeutic effects of mouse adipose-derived stem cells and losartan in the skeletal muscle of injured mdx mice. Cell Transplant. 2015;24(5):939-953.

168. Lesault PF, et al. Macrophages improve survival, proliferation and migration of engrafted myogenic precursor cells into MDX skeletal muscle. PLoS One. 2012;7(10):e46698. 
169.Palumbo R, et al. Extracellular HMGB1, a signal of tissue damage, induces mesoangioblast migration and proliferation. J Cell Biol. 2004;164(3):441-449.

170.Lolmede K, et al. Inflammatory and alternatively activated human macrophages attract vesselassociated stem cells, relying on separate HMGB1- and MMP-9-dependent pathways. JLeukoc Biol. 2009;85(5):779-787.

171. Mori da Cunha MGMC, et al. Fate of mesoangioblasts in a vaginal birth injury model: influence of the route of administration. Sci Rep. 2018;8(1):10604.

172. Gerli MFM, et al. Combined Notch and PDGF signaling enhances migration and expression of stem cell markers while inducing perivascular cell features in muscle satellite cells. Stem Cell Reports. 2019;12(3):461-473.

173. Torrente Y, et al. Identification of a putative pathway for the muscle homing of stem cells in a muscular dystrophy model. J Cell Biol. 2003;162(3):511-520.
174. Perez AL, et al. CXCR4 enhances engraftment of muscle progenitor cells. Muscle Nerve. 2009;40(4):562-572.

175. Giannotta M, et al. Targeting endothelial junctional adhesion molecule-A/ EPAC/ Rap-1 axis as a novel strategy to increase stem cell engraftment in dystrophic muscles. EMBO Mol Med. 2014;6(2):239-258.

176. Farini A, Sitzia C, Erratico S, Meregalli M, Torrente Y. Influence of immune responses in gene/ stem cell therapies for muscular dystrophies. Biomed Res Int . 2014;2014:818107.

177. Mendell JR, et al. Dystrophin immunity in Duchenne's muscular dystrophy. $N$ Engl J Med. 2010;363(15):1429-1437.

178. Skuk D, Tremblay JP. Necrosis, sarcolemmal damage and apoptotic events in myofibers rejected by CD8+ lymphocytes: Observations in nonhuman primates. Neuromuscul Disord. 2012;22(11):997-1005.

179. Noviello M, et al. Inflammation converts human mesoangioblasts into targets of alloreactive immune responses: implications for allogeneic cell therapy of DMD. Mol Ther. 2014;22(7):1342-1352.

180. Kinoshita I, et al. Myoblast transplantation in monkeys: control of immune response by FK506. J Neuropathol Exp Neurol. 1996;55(6):687-697.

181. Vilquin JT, Kinoshita I, Roy R, Tremblay JP. Cyclophosphamide immunosuppression does not permit successful myoblast allotransplantation in mouse. Neuromuscul Disord. 1995;5(6):511-517.

182. Pavlath GK, Rando TA, Blau HM. Transient immunosuppressive treatment leads to long-term retention of allogeneic myoblasts in hybrid myofibers. J Cell Biol. 1994;127(6 Pt 2):1923-1932.

183. Lorant J, et al. Vascular delivery of allogeneic MuStem cells in dystrophic dogs requires only short-term immunosuppression to avoid host immunity and generate clinical/tissue benefits. Cell Transplant. 2018;27(7):1096-1110.

184. Merlini L, Sabatelli P. Improving clinical trial design for Duchenne muscular dystrophy. BMC Neurol. 2015;15(1):153. 